\title{
Coupling 3D Quantitative Interrogation of Weld Microstructure with 3D Models of Mechanical Response
}

\author{
Jonathan D. Madison • Larry K. Aagesen • \\ Corbett C. Battaile · Jeffrey M. Rodelas • \\ Tyler K. C. S. Payton
}

Received: 22 July 2013/Accepted: 1 October 2013/Published online: 12 November 2013

(C) Springer Science+Business Media New York and ASM International 2013

\begin{abstract}
Porosity resulting from linear autogenous laserwelds of 304L stainless steel are non-destructively examined and digitally reproduced by means of micro-computed tomography. These digitized microstructures are then imported into a finite element framework in which the pores are surrounded by an idealized, homogenized geometry, and exposed to a plastic strain-inducing failure load. Variations in equivalent plastic strain, strain at peak load and load-to-failure were all found to bear some correlation with the digitized microstructure's local and global porosity content in simulation. Furthermore, experimental results show agreements in deformation trends predicted by simulation but reveal simulations underestimate both peak load and strain-to-failure.
\end{abstract}

This article is an invited paper selected from presentations at the 2013 Quantitative Metallography Conference and Exposition, held April 4-5, 2013, in San Antonio, Texas, and has been expanded from the original presentation.

J. D. Madison $(\varangle)$. C. C. Battaile

Computational Materials \& Data Science, Sandia National

Laboratories, Albuquerque, NM 87185, USA

e-mail: jdmadis@sandia.gov

L. K. Aagesen

Materials Science \& Engineering, University of Michigan, Ann Arbor, MI 48109, USA

J. M. Rodelas

Metallurgy \& Materials Joining, Sandia National Laboratories, Albuquerque, NM 87185, USA

T. K. C. S. Payton

Materials \& Metallurgical Engineering, New Mexico Institute of Mining \& Technology, Socorro, NM 87801, USA
Keywords Non-destructive examination · Steels · Welding $\cdot$ Laser-based processing $\cdot$ Characterization

\section{Introduction}

Understanding and quantifying the presence of porosity within laser-welds is an area receiving increasing attention and effort [1-5]. Previous work to rigorously quantify porosity in three-dimensions within laser-welds of $304 \mathrm{~L}$ stainless steel has been undertaken, resulting in the identification of porosity size, shape, frequency, directionality, and interspacing distributions, all as functions of three primary processing parameters: focal length, travel speed, and power delivered at the workpiece $[6,7]$. The work presented here is a continuation of that effort and is focused on leveraging the benefits of meticulous characterization with finite element modeling toward some level of prediction relative to mechanical response in this highly utilized material system.

While there are many microstructural factors that contribute to a material's mechanical response, the effect of porosity in $304 \mathrm{~L}$ stainless steel is not well understood. Authors have reported the presence of porosity having no effect on mechanical response [8] while others have shown increasing porosity content can either strengthen or degrade tensile strength in 304L [9]. This work seeks to isolate and evaluate the relative effect of porosity by strictly limiting the factors used to generate the welds of interest, thereby effectively bounding the parameter space to produce three readily identifiable regimes of porosity content $[2,3]$. The mechanical response of these welds are then evaluated by both finite element simulation and compared with mechanical tensile tests. 


\section{Experimental Method \& Computational Approach}

Here a subset of welds from a larger test matrix [6], and reported elsewhere [7], have been revisited for this study. This subset consists of six welds, produced at three constant weld travel speeds; 1016, 1524, and $2032 \mathrm{~mm} \mathrm{~min}^{-1}$, two laser optic focal lengths, 80 and $120 \mathrm{~mm}$, and one power: $1,200 \mathrm{~W}$. Autogenous argon-shielded Nd:YAG laser partial-penetration welds with standing-edge joint geometry were produced by joining two $2.54 \times 10.16 \times 0.1 \mathrm{~cm}$ plates of $304 \mathrm{~L}$ stainless steel having the following elemental composition: $\mathrm{Fe}-0.04 \mathrm{C}-18.12 \mathrm{Cr}-1.21 \mathrm{Mn}-8.09 \mathrm{Ni}-0.028 \mathrm{~N}-$ 0.022P-0.001S-0.34Si (wt\%).

Following welding, each weld was examined via microcomputed tomography, yielding full three-dimensional reconstructions of the porosity content throughout each weld. The resolution of each data set was nominally $31 \times 31 \times 31 \mu \mathrm{m}$ voxel $^{-1}$. Each weld produced varying amounts of porosity as identified by traditional metallographic inspection and advanced three-dimensional

Table 1 Weld matrix pore volume fractions

\begin{tabular}{llll}
\hline & $\begin{array}{l}1016 \\
\mathrm{~mm} \mathrm{~min}\end{array}$ & $\begin{array}{l}1,524 \\
\mathrm{~mm} \mathrm{~min}^{-1}\end{array}$ & $\begin{array}{l}2,032 \\
\mathrm{~mm} \mathrm{~min}\end{array}$ \\
\hline $\begin{array}{c}80 \mathrm{~mm} \text { lens } \\
1,200 \mathrm{~W}\end{array}$ & $0.52 \%$ & $0.11 \%$ & $0.06 \%$ \\
$\begin{array}{c}120 \mathrm{~mm} \text { lens } \\
1,200 \mathrm{~W}\end{array}$ & $0.56 \%$ & $0.17 \%$ & $0.15 \%$ \\
\hline
\end{tabular}

Table 2 Weld matrix average pore volumes

\begin{tabular}{llll}
\hline & $\begin{array}{l}1,016 \\
\mathrm{~mm} \mathrm{~min}\end{array}$ & $\begin{array}{l}1,524 \\
\mathrm{~mm} \mathrm{~min}^{-1}\end{array}$ & $\begin{array}{l}2,032 \\
\mathrm{~mm} \mathrm{~min}\end{array}$ \\
\hline $\begin{array}{c}80 \mathrm{~mm} \text { lens } \\
1,200 \mathrm{~W}\end{array}$ & $0.075 \mathrm{~mm}^{3}$ & $0.005 \mathrm{~mm}^{3}$ & $0.004 \mathrm{~mm}^{3}$ \\
$\begin{array}{c}120 \mathrm{~mm} \text { lens } \\
1,200 \mathrm{~W}\end{array}$ & $0.14 \mathrm{~mm}^{3}$ & $0.009 \mathrm{~mm}^{3}$ & $0.003 \mathrm{~mm}^{3}$ \\
\hline
\end{tabular}

Fig. 1 Porosity in laser-welded 304L stainless steel shown as (a) an initial three-dimensional reconstruction, (b) meshed pores, (c) hexahedral elements for finite element analysis

characterization. For convenience, the abbreviated weld matrix and nominal pore fraction for each weld case are summarized in tabular form, see Tables 1 and 2. For additional details of porosity characterization, the reader is referred elsewhere [6, 7].

Using the obtained three-dimensional reconstructions, meshes of hexahedral elements were imported into Jas 3D, a Sandia National Laboratories-developed three-dimensional finite element code designed to solve large quasistatic nonlinear mechanics problems. Images of the reconstructed, meshed, and imported elements can be seen in Fig. 1.

The pores were instantiated as voids and a fixed rectangular volume was extruded around the pores with fixed boundary conditions enclosing the simulation domain within a rectilinear body having the linear series of pores oriented along the body's length or major axis. The surrounding volume was ascribed material properties derived from previous experimental work with porosity-containing welds of $304 \mathrm{~L}$ having largely similar processing and thermal histories [8]. These values are summarized in Table 3. Each mesh was then subjected to a tensile load and strained to failure in which an elastic, power-law plastic constitutive model was used. In the case of this experiment, the authors define failure as the loss of loadbearing capability at a level equal to or lower than the initial yield stress. To increase the efficiency of the finite element calculations, meshes were downsized by a factor of four. Redundant cases run without downsizing showed

Table 3 Material model constants

\begin{tabular}{lll}
\hline Material property & Value & Units \\
\hline Young modulus $(E)$ & $2 \times 10^{5}$ & $\mathrm{MPa}$ \\
Poisson's ratio $(v)$ & 0.331 & \\
Yield stress $\left(\sigma_{y}\right)$ & 280 & $\mathrm{MPa}$ \\
Hardening constant $(K)$ & 474.0 & $\mathrm{MPa}$ \\
Hardening exponent $(n)$ & 0.32 & \\
\hline
\end{tabular}

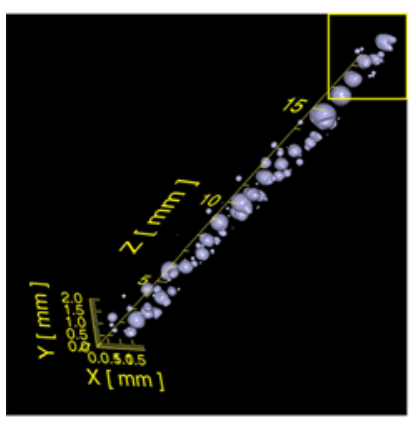

(a)

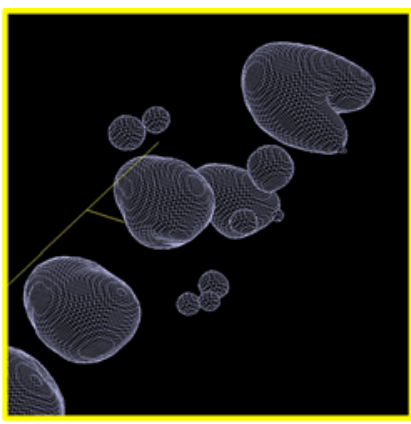

(b)

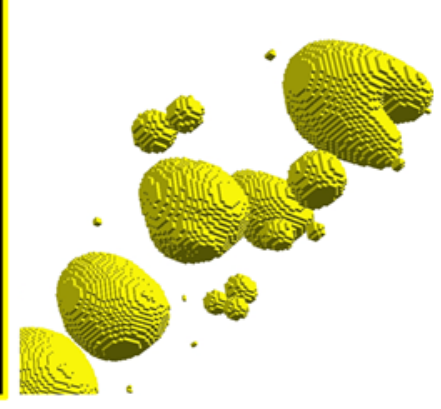

(c) 


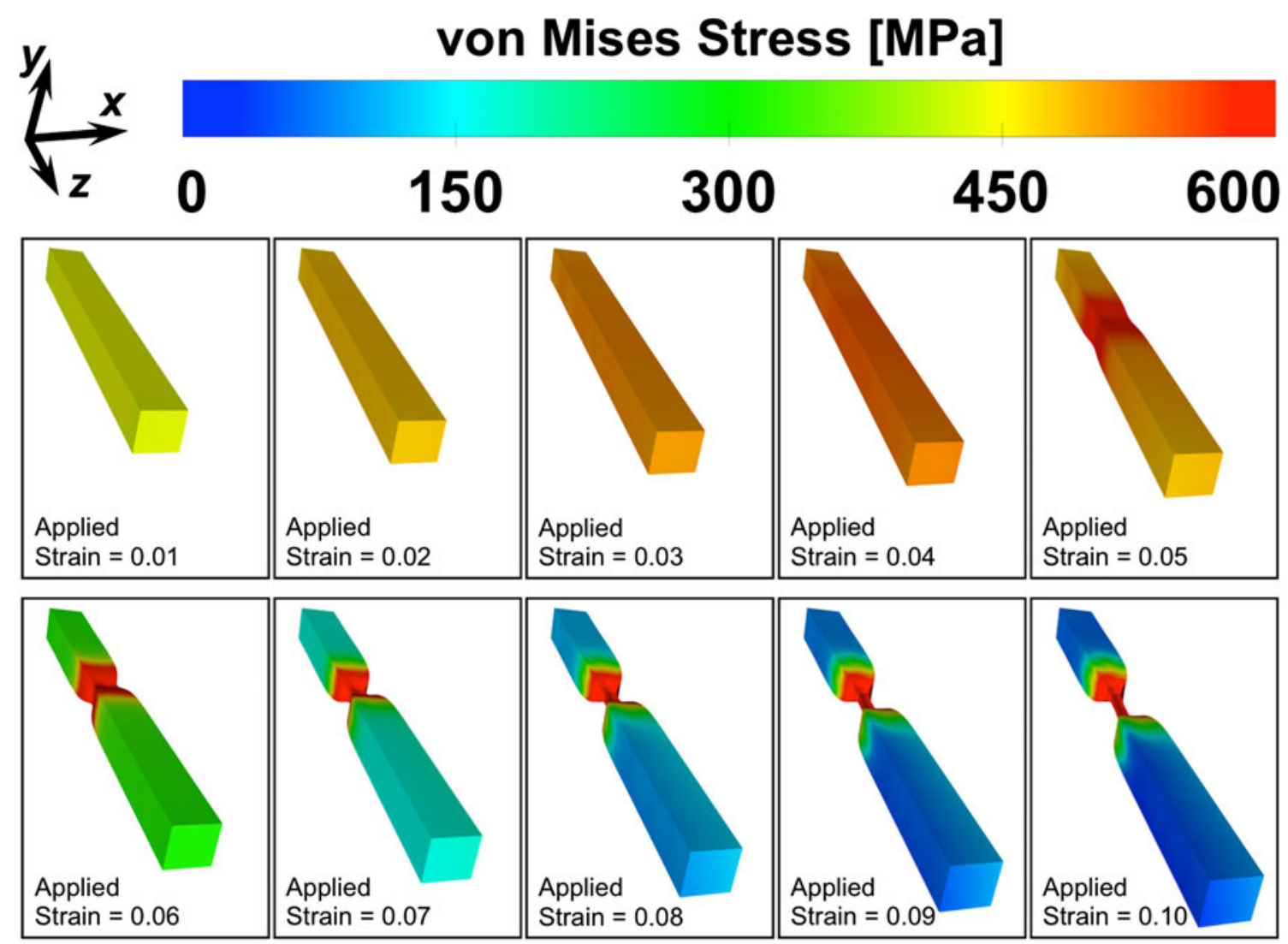

Fig. 2 Visualization of finite element simulation showing strain progression in pore-containing body

(a)

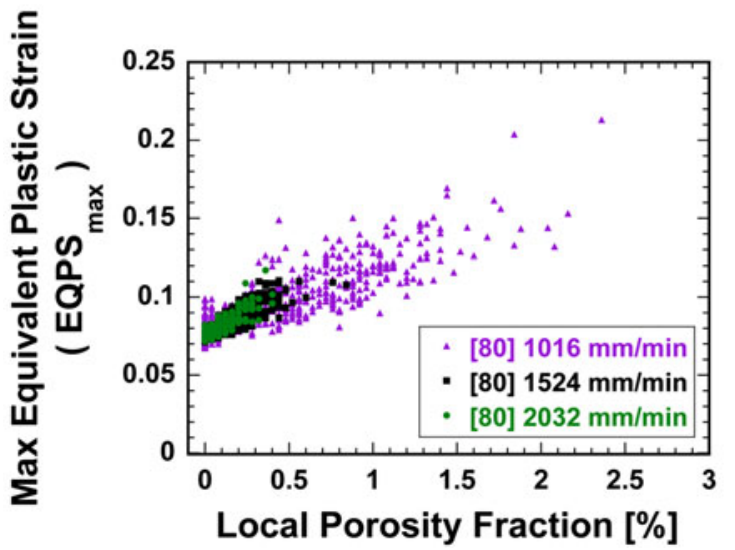

(b)

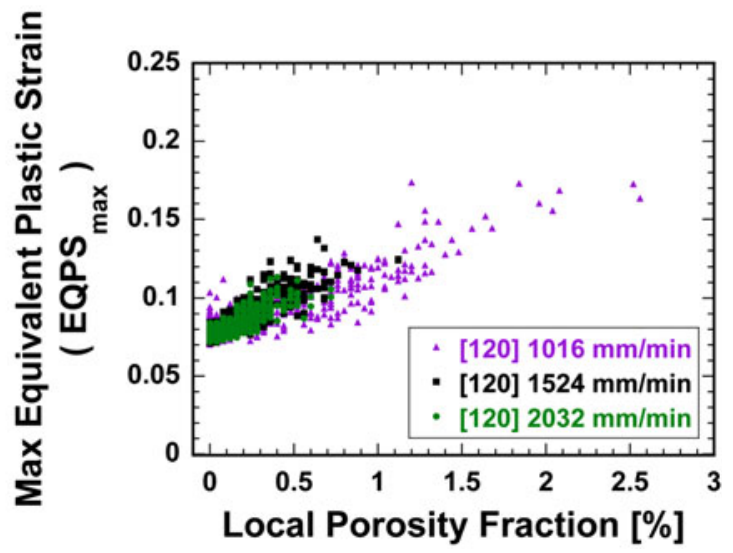

Fig. 3 Maximum equivalent plastic strain as a function of local porosity fraction in (a) $80 \mathrm{~mm}$ series welds and (b) $120 \mathrm{~mm}$ series welds

neither significant variation in the calculations nor any mesh size dependency of the result.

Following welding three-dimensional characterization and simulation, mechanical test specimens were prepared by removing the unwelded ligament from the partial-penetration standing-edge welds, resulting in elongated rectangular cross-sectional samples roughly matching the rectilinear geometries previously modeled. It should be noted, due to machining limitations, physical sample dimensions did not bear exact matches to simulation domains. These samples were then strained to failure to serve as a nominal comparison to finite element simulations. 


\section{Results}

The straining behavior observed in all simulations was characterized by rapid localization of stress at a specific point in the pore-containing rectilinear body with a rapid drop in all load-bearing capability immediately following arrival at peak load. Images of one finite element simulation showing the mesh undergoing increasing strain and subsequent necking are shown in Fig. 2. The authors wish to note, there are no fracture mechanics incorporated into the model, therefore; while the necking behavior appears exaggerated at long simulation times, the stress response illustrates loss of load-bearing capability long before excessive necking.

In comparing the specific strain response to both the local and global porosity content, two interesting correlations are observed. By dividing each simulation domain into elemental slices perpendicular to the orientation of the applied tensile load throughout its length, measures of the local porosity content are returned. These values ranged from zero to approximately $2.5 \%$ in any given slice. As shown in Fig. 3, for both the 80 and $120 \mathrm{~mm}$ focal distance

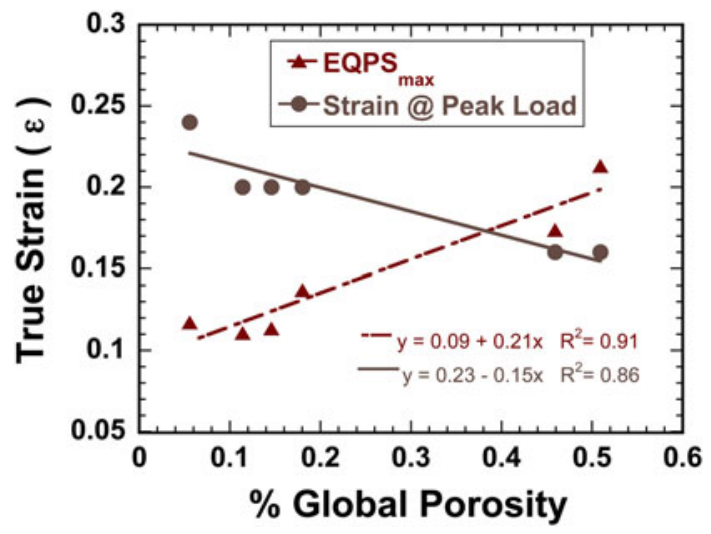

Fig. 4 Stress-strain curves for both simulation and mechanical tensile tests

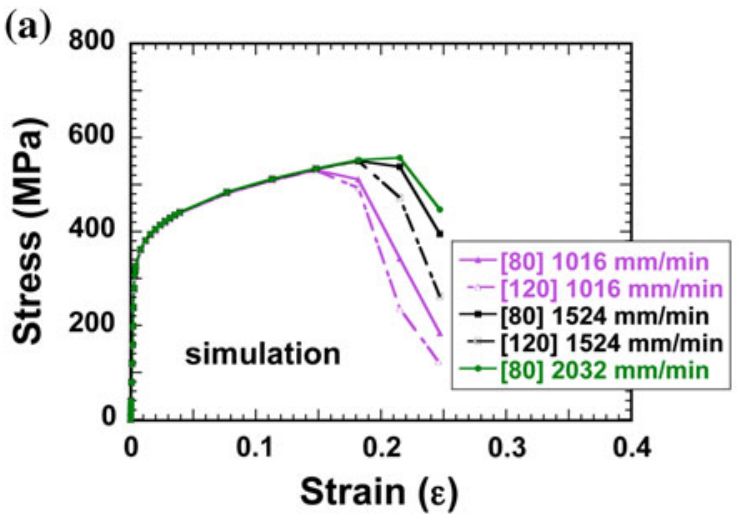

welds, with increasing local porosity content, a higher maximum equivalent plastic strain was returned. As a result, the highest localized plastic strains were observed in welds produced using a $1,016 \mathrm{~mm} \mathrm{~min}^{-1}$ travel speed. Such welds also contain the greatest overall pore fraction of voids and comparably, the largest average void size.

By strictly considering the global porosity content of the simulation domains, it was observed that with increasing global pore fraction, while equivalent plastic strain increases, the total amount of strain the microstructure can endure before losing load-bearing capability decreases, Fig. 4. This would suggest either a greater pore fraction, or greater average porosity volume has the ability to limit and/or decrease the ductile response of $304 \mathrm{~L}$ as compared to smaller pore volume fractions or smaller average pore size.

In comparison with mechanical tensile tests, simulations reliably reproduce both the initial yielding and hardening behavior observed in experiment, Fig. 5. Experimental results are consistent with the simulation predictions of smaller voids which comprise an overall smaller volume fraction, sustaining a slightly higher peak load and greater elongation prior to failure. Unfortunately, simulations also underestimate peak stress by approximately $100 \mathrm{MPa}$ and total strain-to-failure by a factor of 3 .

\section{Discussion}

These results show that while mechanical response can be rather similar for a collection of laser-welds in 304L, their local and global porosity content contribute to the mechanical response. While the variation illustrated here is not dramatic, the results indicate a subtle systematic change in processing parameters can produce a tractable change in the microstructure, which in turn can effect a systematic change in the stress-strain response. As

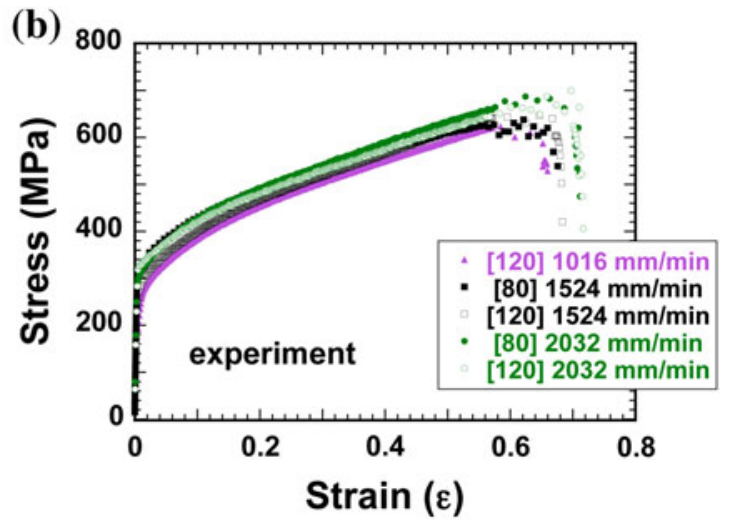

Fig. 5 True strain versus global porosity content of simulations domains 
predicted in simulation and confirmed by experiment, a comparatively lower volume fraction of smaller volume pores distributed throughout the fusion zone can sustain a higher stress to failure and accommodate greater elongation in tension. The authors suggest the reduction in strainto-failure for cases having slower travel speeds and larger voids are supported, if not partly explained, by two observations from the simulations. First, the simulations show, higher local porosity levels allow for a greater distribution and higher maximum equivalent plastic strains experienced throughout the microstructure, Fig. 3. Secondly, the occurrence of lower strains at peak load corresponds to higher levels of global porosity content across samples examined, Fig. 4. These suggest a microstructure having a lower volume fraction of smaller pores will provide greater ductility and a higher failure strain prior to necking and failure. While this study does not distinguish whether the behavior observed is primarily attributable to the effect of the overall volume fraction, local void spacing or a combination of the two, decoupling the contribution of each will be the work of a future study.

\section{Conclusions}

- While the simulation model employed here underestimates the peak stress and total strain-to-failure, imagebased models of pore geometries can be directly imported into finite element code to help understand the mechanical response of pore containing welds of 304L stainless steel.

- As shown via simulation and experiment, lower volume fractions of smaller average size pores sustain greater strains and higher peak stress prior to failure when compared to collections of larger voids constituting a higher volume fraction in $304 \mathrm{~L}$ stainless steel autogenous welds.
- Although samples with larger voids can experience higher localized maximum equivalent plastic strain, these arrangements of voids appear to yield to necking at lower stresses and lower strain.

Acknowledgments Sandia National Laboratories is a multi-program laboratory managed and operated by Sandia Corporation, a wholly owned subsidiary of Lockheed Martin Corporation, for the US Department of Energy's National Nuclear Security Administration under contract DE-AC04-94AL85000.

\section{References}

1. J.D. Tucker, T.K. Nolan, A.J. Martin, G.A. Young, Effect of travel speed and beam focus on porosity in alloy 690 laser welds. JOM 64(12), 1409-1417 (2012)

2. J.T. Norris, M.J. Perricone, R.A. Roach, K.M. Faraone, C.M. Ellison, In Sandia National Laboratories, for the Department of Energy, SAND2007-1051 (2007)

3. J.T. Norris, C.V. Robino, D.A. Hirschfeld, M.J. Perricone, Effects of laser parameters on porosity formation: investigating millimeter scale continuous wave Nd:YAG laser welds. Weld. J. 90, 198-203 (2011)

4. A. Haboudou, P. Peyre, A.B. Vannes, G. Peix, Reduction of porosity content generated during Nd:YAG laser welding of A356 and AA5083 aluminum alloys. Mater. Sci. Eng. A A363, 40-52 (2003)

5. J. Zhou, H.-L. Tsai, Porosity formation and prevention in pulsed laser welding. Trans. ASME 129, 1014-1024 (2007)

6. J. Madison, L.K. Aagesen, Sandia National Laboratories, for the Department of Energy, SAND2012-4474 (2012)

7. J. Madison, L.K. Aagesen, Quantitative characterization of porosity in laser welds of stainless steel. Scr. Mat. 67(9), 783-786 (2012)

8. B.L. Boyce, P.L. Reu, C.V. Robino, The constitutive behavior of laser welds in $304 \mathrm{~L}$ stainless steel determined by digital image correlation. Metall. Mater. Trans. A 37A, 2481-2492 (2006)

9. T.Y. Kuo, S.L. Jeng, Porosity reduction in Nd-YAG laser welding of stainless steel and inconel alloy by using a pulsed wave. J. Phys. D Appl. Phys. 38, 722-728 (2005) 